\title{
Assessment of efficacy with radioiodine treatment in Benign Hyperthyroid disease across two centres
}

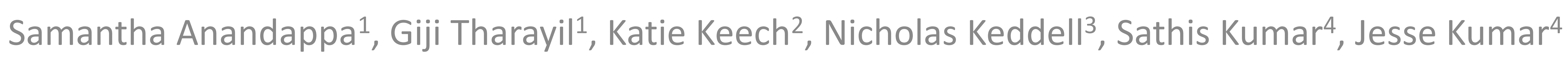

${ }^{1}$ Diabetes and Endocrine Specialist Registrar, ${ }^{2}$ Core Medical Trainee, ${ }^{3}$ Foundation Doctor, ${ }^{4}$ Endocrine Consultant

\section{INTRODUCTION}

- The indications of Radioiodine (131I) in benign thyroid disease include therapy for hyperthyroidism - Graves' disease, Toxic goitre (solitary toxic adenomas or multinodular goitre) and euthyroid goitre

\section{AIMS OF THE PROJECT}

Establish demographics and prevalence of the treatment population

To ensure dosage and indication compliance with national guidelines

To determine the efficacy of the treatment through thyroid function outcomes

\section{METHOD}

Retrospective data collection

Excel database used

Data collected for all patients receiving Radioiodine treatment for benign thyroid conditions between 1st June 2015 and 1st June 2016

Across two prescribing sites:

Site 1 = endocrinology trained prescriber Site 2 = oncology trained prescriber

\section{RESULTS}

45 patients identified having radioiodine treatment during time period analysed, two of whom were lost to follow up and therefore excluded

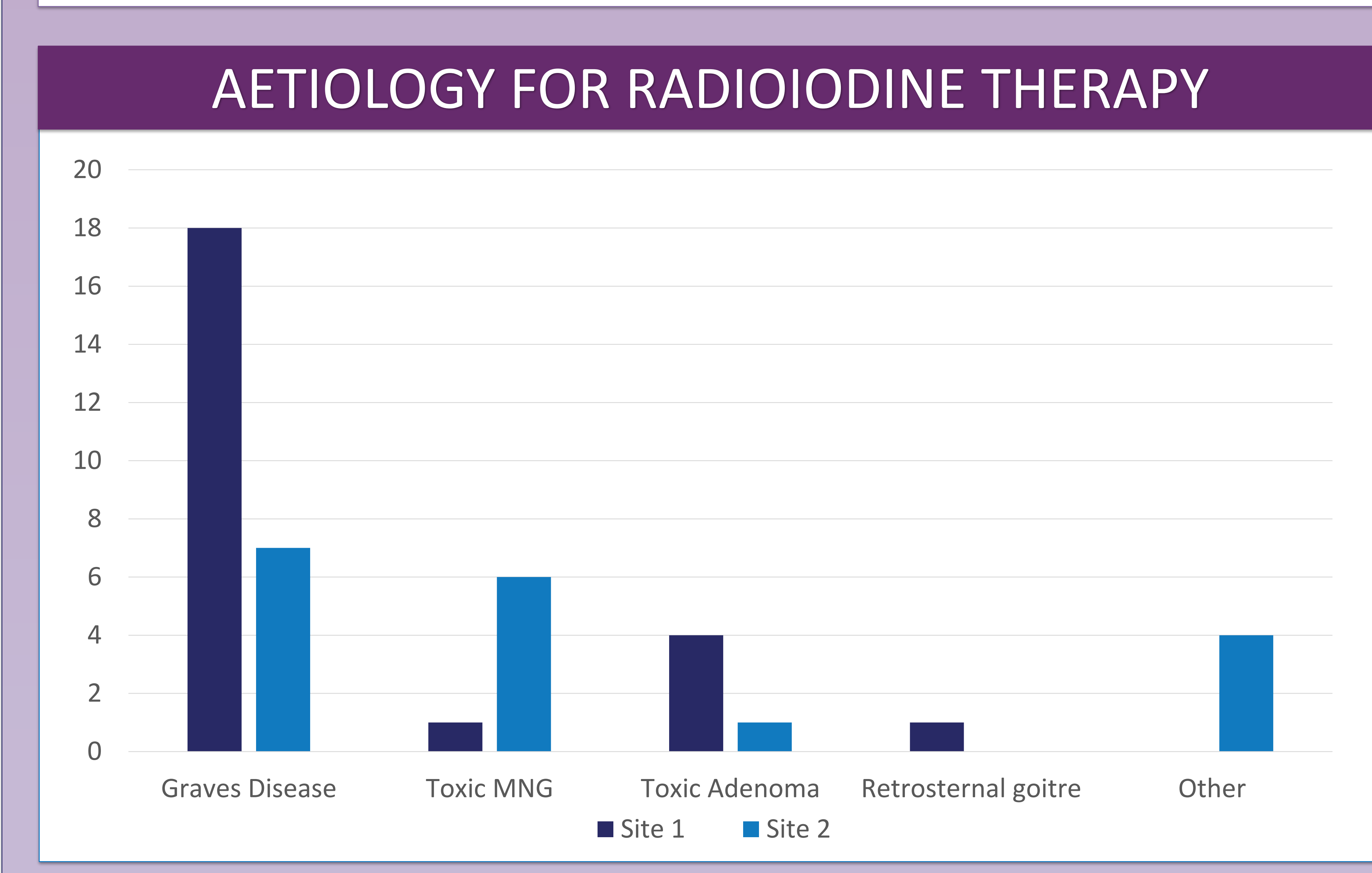

\section{EYE DISEASE}

All patients had active eye disease excluded

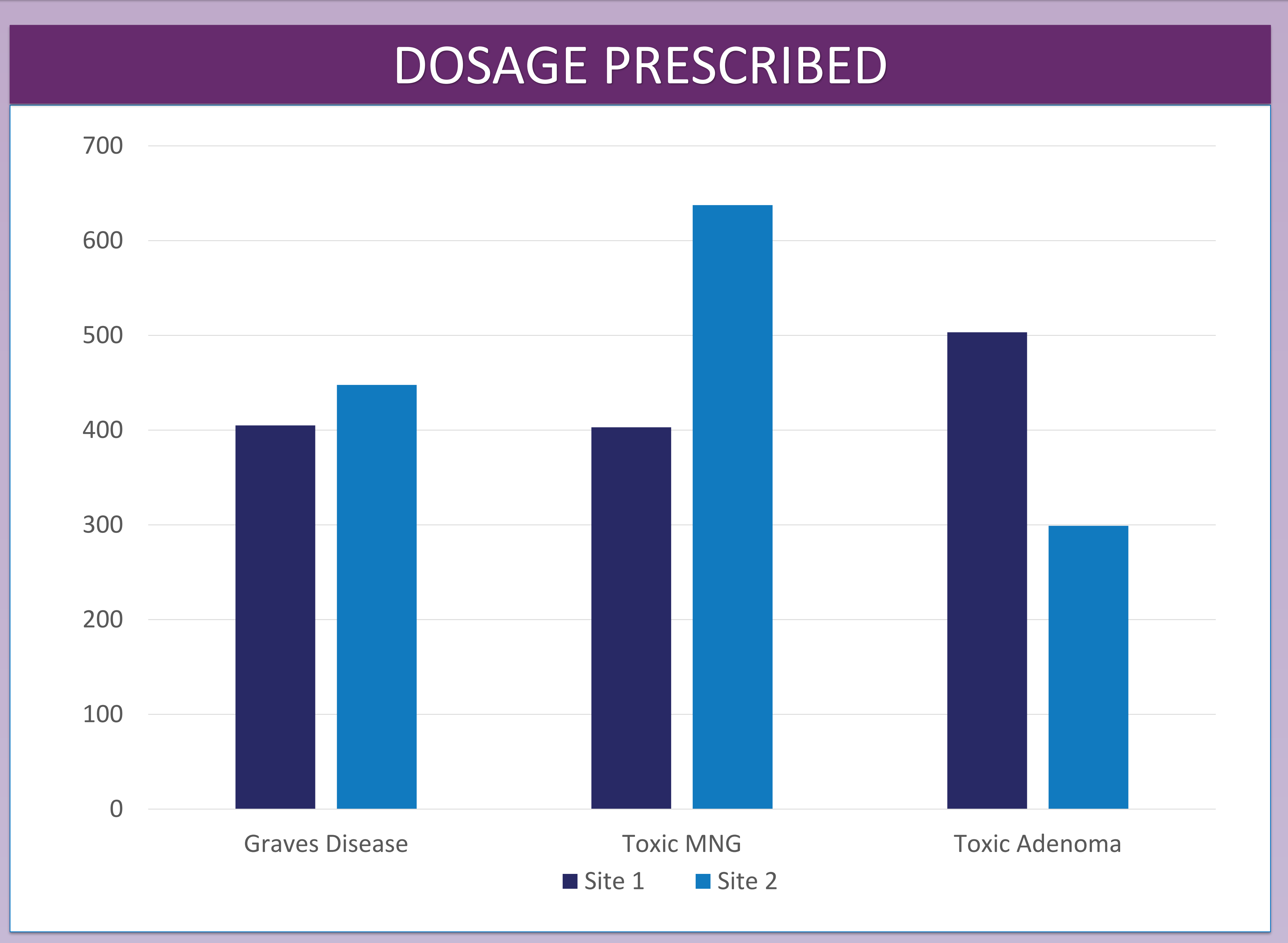

\section{TREATMENT OUTCOME}

The overall data showed a cure rate (those achieving euthyroidism or hypothyroidism) for Graves' Disease of $100 \%$ by 12 months

\section{CONCLUSION}

There was appropriate adherence to national guidance* at both sites and lower doses were used with similar efficacy. Hence further comparisons with other centres using dosage calculations may be a useful guide in reflective practice

Thyroid eye clinics for exclusion and stabilisation of eye disease prior to radioiodine treatment should be utilised (where possible) to exclude active Thyroid Eye Disease

Raising awareness of effectiveness and safety of radioiodine to instigate earlier referral in recurrent thyrotoxicosis of benign thyroid disease

Need to have longer term follow up to include relapse rates \& also future hypothyroidism in RAI treated patients

\section{REFERENCE}

${ }^{*}$ Royal College of Physicians. Radioiodine in the management of benign thyroid disease Clinical guidelines. Report of a Working Party 2007 